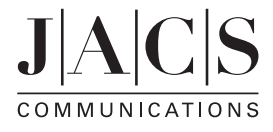

Published on Web 01/06/2005

\title{
The Interaction of 1,1'-Diisocyanoferrocene with Gold: Formation of Monolayers and Supramolecular Polymerization of an Aurophilic Ferrocenophane
}

\author{
Ulrich Siemeling, ${ }^{*}, \dagger$ Dag Rother,${ }^{\dagger}$ Clemens Bruhn, ${ }^{\dagger}$ Heinrich Fink, ${ }^{\dagger}$ Tobias Weidner, ${ }^{\dagger}$ Frank Träger, ${ }^{\dagger}$

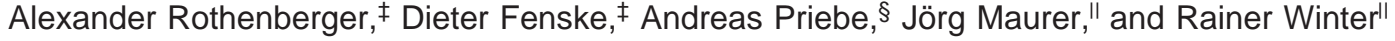 \\ Department of Science and Center for Interdisciplinary Nanostructure Science and Technology (CINSaT), \\ University of Kassel, D-34109 Kassel, Germany, Institute of Inorganic Chemistry, University of Karlsruhe, D-76128 \\ Karlsruhe, Germany, Kirchhoff Institute for Physics, University of Heidelberg, D-69120 Heidelberg, Germany, and \\ Institute of Inorganic Chemistry, University of Stuttgart, D-70569 Stuttgart, Germany
}

Received October 20, 2004; E-mail: siemeling@uni-kassel.de

Isocyanides are important ligands in coordination chemistry. ${ }^{1}$ They are of great current interest in surface chemistry, where their binding on gold and other metals has been addressed using bi- and tridentate isocyanides. ${ }^{2}$ However, despite their attractive properties, the number of oligodentate isocyanides has remained small in comparison to other prominent ligand families. ${ }^{3}$ Because of our interest in redox-functionalized ligands, ${ }^{4} 1,1^{\prime}$-diisocyanoferrocene ${ }^{5}$ (1) has caught our attention. $\mathbf{1}$ is a potentially bidentate ligand, whose chemistry, much to our surprise, has remained unexplored thus far. Its monodentate analogue isocyanoferrocene (2), however, has already been investigated in detail. $\mathbf{2}$ behaves like an aryl isocyanide in complexes such as $(\mathbf{2}) \mathrm{Cr}(\mathrm{CO})_{5}{ }^{6} \mathrm{IR}$ data indicate that $\mathbf{1}$ behaves analogously. It readily forms $(\mathbf{1})\left[\mathrm{Cr}(\mathrm{CO})_{5}\right]_{2}$ with 2 equiv of $\mathrm{Cr}(\mathrm{CO})_{5}(\mathrm{THF})$, whereupon the $v(\mathrm{NC})$ band shifts from 2118 to $2142 \mathrm{~cm}^{-1}$. This effect is similar to that observed in the case of (2) $\mathrm{Cr}(\mathrm{CO})_{5} \cdot{ }^{6 \mathrm{~d}}(\mathbf{1})\left[\mathrm{Cr}(\mathrm{CO})_{5}\right]_{2}$ was structurally characterized by X-ray diffraction. It exhibits an eclipsed orientation of the cyclopentadienyl rings with a synclinal arrangement of the two substituents. Spectroelectrochemical investigations have revealed that oxidation of the ferrocene unit of $(\mathbf{1})\left[\mathrm{Cr}(\mathrm{CO})_{5}\right]_{2}\left(E^{\circ \prime}=0.55 \mathrm{~V}\right.$ vs ferrocenium/ ferrocene) leads to a shift of the isocyanide band to $2017 \mathrm{~cm}^{-1}$, a fact that can be explained by a decreased net electron donor ability of $\mathbf{1}^{+}$.

The distance between the two Cp decks of ferrocene is $3.32 \AA$, and the molecule shows ball-bearing-like features, since the barrier for ring rotation is very small. ${ }^{7}$ In view of these properties, an investigation of the coordination behavior of $\mathbf{1}$ toward gold(I) seemed interesting, since in the solid-state aurophilic interactions between neighboring molecules in isocyanide gold(I) complexes can lead to intermolecular $\mathrm{Au}-\mathrm{Au}$ contacts below the sum of the estimated van der Waals radii $(3.6 \AA) .8$, We envisaged that here intramolecular $\mathrm{Au}-\mathrm{Au}$ interactions lead to an unprecedented diaura[6]ferrocenophane. In general, two-coordinate gold(I) compounds experience attractive aurophilic interactions if the $\mathrm{Au}-\mathrm{Au}$ separations are below $3.6 \AA$; their strength can be up to $10 \mathrm{kcal} \mathrm{mol}^{-1}$ for a dimeric unit, similar to standard hydrogen bonds. ${ }^{8,10}$ The energetic contribution of longer $\mathrm{Au}-\mathrm{Au}$ contacts is negligible. ${ }^{8 \mathrm{a}}$ Aurophilic association can also lead to oligomers and one- and twodimensional polymers.

In comparison to ligands such as $\mathrm{R}_{3} \mathrm{P}, \mathrm{R}_{2} \mathrm{~S}$, etc., isocyanides appear to weaken aurophilic bonding in gold(I) compounds, ${ }^{11 \mathrm{a}}$ as witnessed by $\mathrm{Au}-\mathrm{Au}$ separations close to the threshold value of 3.6 ̊̊. ${ }^{9,11}$ Very short distances between (RNC)AuX molecules have

$\dagger$ University of Kassel.

\# University of Karlsruhe.

$\S$ University of Heidelberg.

" University of Stuttgart.

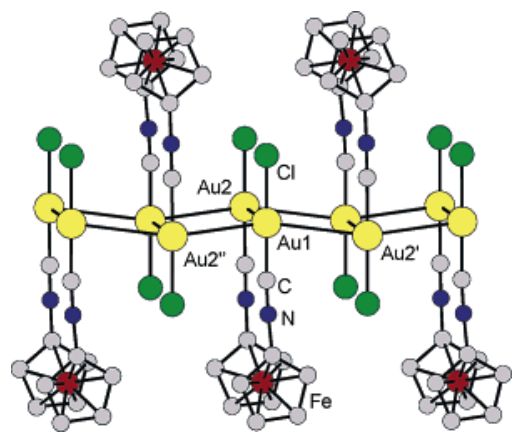

Figure 1. View of the association of $\mathbf{1}$ in the crystal. Selected bond lengths: Au1-Au2 3.336(1), Au1-Au2' 3.484(1), Au1-Au2" 3.354(1) $\AA$ (Au2': $\left.2-x, 1-y, 1-z ; A u 2^{\prime \prime}: 1-x, 1-y, 1-z\right)$.

been observed for species that form dimeric aggregates in the solid state. Typical examples are $\left[\mathrm{MeOC}(\mathrm{O}) \mathrm{CH}_{2} \mathrm{NC}\right] \mathrm{AuI}(3.19 \AA)$ and (MesNC)AuCl (3.34 ̊̊). ${ }^{9 \mathrm{~d}}$ Gold(I) complexes of oligodentate isocyanides are rare. The only compound of this type that shows some evidence for intramolecular $\mathrm{Au}-\mathrm{Au}$ interactions is $(\mathrm{dmb})(\mathrm{AuCN})_{2}(\mathrm{dmb}=1,8$-diisocyano- $p$-menthane $) .{ }^{12}$ The isocyanide groups are located on the same side of the $\mathrm{dmb}$ ligand, binding two AuCN units with an $\mathrm{Au}-\mathrm{Au}$ separation of $3.54 \AA$. The molecules are aggregated into antiparallel dimers with intermolecular $\mathrm{Au}-\mathrm{Au}$ distances of $3.49 \AA$.

The reaction of 1,1'-diisocyanoferrocene (1) with $\mathrm{AuCl}\left(\mathrm{SMe}_{2}\right)$ in dichloromethane afforded $\left[(\mathbf{1})(\mathrm{AuCl})_{2}\right]_{\infty}$, irrespective of the stoichiometry of the reaction. The compound precipitated immediately upon addition of the first drop of reagent solution, irrespective of whether 1 was added to $\mathrm{AuCl}\left(\mathrm{SMe}_{2}\right)$ or vice versa. $\left[(\mathbf{1})(\mathrm{AuCl})_{2}\right]_{\infty}$ proved to be insoluble in all common solvents, including hot acetonitrile, pyridine, 1,2-dichloroethane, dimethyl sulfide, as well as DMSO and DMF. The polymer undergoes ligand substitution with $t \mathrm{BuNC}$ and $\mathrm{Ph}_{3} \mathrm{P}$ in dichloromethane, liberating uncoordinated 1. Small single crystals of $\left[(\mathbf{1})(\mathrm{AuCl})_{2}\right]_{\infty}$ were obtained by a diffusion method. The result of the single-crystal $\mathrm{X}$-ray diffraction study is shown in Figure 1.

The molecules adopt the anticipated 3,4-diaura-[6]ferrocenophane structure. The intramolecular $\mathrm{Au}-\mathrm{Au}$ distance is $3.34 \AA$, which is essentially identical to the distance between the $\mathrm{Cp}$ rings in ferrocene and to the $\mathrm{Au}-\mathrm{Au}$ separation observed for (MesNC)$\mathrm{AuCl}$ (vide supra). Whereas ( $\mathrm{MesNC}) \mathrm{AuCl}$ is aggregated into dimers, the $(\mathbf{1})(\mathrm{AuCl})_{2}$ units form one-dimensional chains. The zipperlike arrangement of the molecules leads to a corrugated ribbon of gold atoms composed of two parallel chains, each exhibiting alternating $\mathrm{Au}-\mathrm{Au}$ distances of 3.35 and $3.48 \AA$. 


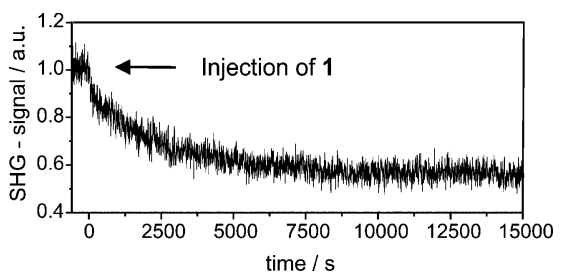

Figure 2. SHG signal recorded during adsorption of $\mathbf{1}$ on a gold substrate from $30 \mu \mathrm{M}$ acetonitrile solution. The arrow indicates the time at which the pure solvent was exchanged by the solution of $\mathbf{1}$.

The structural and functional similarities of aurophilic and hydrogen bonding have been emphasized in recent studies. ${ }^{13}$ In particular, a striking structural similarity between isocyanide complexes $\mathrm{Me}\left(\mathrm{CH}_{2}\right)_{n-1} \mathrm{NCAuCl}$ and primary alcohols $\mathrm{Me}\left(\mathrm{CH}_{2}\right)_{n} \mathrm{OH}$ has been pointed out. ${ }^{11 \mathrm{~b}}$ In this context, we note that the conformation and aggregation of the $(\mathbf{1})(\mathrm{AuCl})_{2}$ units closely resemble that of $\mathrm{Fe}\left[\mathrm{C}_{5} \mathrm{H}_{4}(\mathrm{CHMeOH})\right]_{2}$, where intramolecular hydrogen bonding occurs between the two alcoholic substituents; the molecules are aggregated into one-dimensional chains through intermolecular hydrogen bonds, with an antiparallel zipperlike arrangement of neighboring molecules. ${ }^{14}$

The insoluble nature of $\left[(\mathbf{1})(\mathrm{AuCl})_{2}\right]_{\infty}$ is unique for compounds of this kind and, in conjunction with the structural data, indicative of an effective balance between intra- and intermolecular aurophilicity. In view of the great current interest in metal-containing polymers, ${ }^{15}$ we note that $\left[(\mathbf{1})(\mathrm{AuCl})_{2}\right]_{\infty}$ is a new type of polymer with precious metal atoms in the backbone. ${ }^{16}$

The chemisorption of $\mathbf{1}$ on polycrystalline gold from acetonitrile solution was investigated in situ and in real time by using optical second-harmonic generation (SHG). ${ }^{17}$ Adsorption of $\mathbf{1}$ leads to a decrease of the SHG signal due to localization of electrons from the spill out (Figure 2). The data are in perfect agreement with first-order Langmuir kinetics, which indicates direct adsorption of 1 from solution without intermediate states.

Ellipsometric measurements afford an average film thickness value of $14.1 \AA$. This is in good agreement with the expected value of $8.8 \AA$ estimated from X-ray data of $\left[(\mathbf{1})(\mathrm{AuCl})_{2}\right]_{\infty}$, since the dimensions of monomolecular, and especially ferrocenyl-containing, films are generally overestimated by ellipsometry. ${ }^{18}$ Monolayer formation is further supported by Fourier transform infrared reflection absorption spectroscopy. Comparison of spectra obtained with the modified gold substrate and those obtained from neat 1 reveals characteristic differences. The out-of-plane $\delta(\mathrm{CH})$ bands at 1040,1028 , and $817 \mathrm{~cm}^{-1}$ are decreased almost below noise level. This confirms parallel orientation of the cyclopentadienyl ring plane with respect to the surface normal, ${ }^{19}$ as expected for the binding of both isocyano groups. On the other hand, in-plane modes such as $v(\mathrm{NC}), v(\mathrm{CC})$, and $\delta(\mathrm{CH})$ and ring distortion found in the IR spectrum of neat $\mathbf{1}$ at 2118, 1543, 1095, and $855 \mathrm{~cm}^{-1}$, respectively, are clearly identified in the spectrum of $\mathbf{1}$ on gold. Interaction with the substrate leads to a strong polarization of lone pair electron density into the metal and causes a shift of the $v(\mathrm{NC})$ band from 2118 to $2181 \mathrm{~cm}^{-1}$. This compares well with results obtained with other isocyanides ${ }^{2}$ and also with the value of 2226 $\mathrm{cm}^{-1}$ found for $\left[(\mathbf{1})(\mathrm{AuCl})_{2}\right]_{\infty}$. There is no indication for any surfaceunbound isocyano groups in the film. The section from the crystal structure of $\left[(\mathbf{1})(\mathrm{AuCl})_{2}\right]_{\infty}$ shown in Figure 1 may be taken as a model, cum grano salis, for the arrangement of $\mathbf{1}$ in self-assembled monolayers on gold.

Acknowledgment. We dedicate this paper to Prof. Hubert Schmidbaur on the occasion of his 70th birthday.
Supporting Information Available: Preparative details and analytical and spectroscopic data. X-ray structural data for $(\mathbf{1})\left[\mathrm{Cr}(\mathrm{CO})_{5}\right]_{2}$ and $\left[(\mathbf{1})(\mathrm{AuCl})_{2}\right]_{\infty}$ in CIF format. This material is available free of charge via the Internet at http://pubs.acs.org.

\section{References}

(1) See, for example: (a) Elschenbroich, C. Organometallchemie, 4th ed.; Teubner: Stuttgart, Germany, 2003; Chapter 14.6. (b) Singleton, E. Oosthuizen, H. E. Adv. Organomet. Chem. 1983, 22, 209-310. (c) Treichel, P. M. Adv. Organomet. Chem. 1973, 11, 21-86. (d) Malatesta L.; Bonati, F. Isocyanide Complexes of Metals; Academic Press: New York, 1969.

(2) Recent references: (a) Murphy, K. L.; Tysoe, W. T.; Bennett, D. W Langmuir 2004, 20, 1732-1738. (b) Henderson, J. I.; Feng, S.; Bein, T.; Kubiak, C. P. Langmuir 2000, 16, 6183-6187. (c) Lin, S.; McCarley, R. L. Langmuir 1999, 15, 151-159. (d) Ontko, A. C.; Angelici, R. J. Langmuir 1998, 14, 3071-3078.

(3) Reviews: (a) Harvey, P. D. Coord. Chem. Rev. 2001, 219-221, 17-52. (b) Hahn, F. E. Angew. Chem. 1993, 105, 681-696; Angew. Chem., Int. Ed. Engl. 1993, 32, 650-665.

(4) Reviews: (a) Hirao, T. Coord. Chem. Rev. 2002, 226, 81-91. (b) Allgeier, A. M.; Mirkin, C. A. Angew. Chem. 1998, 110, 936-952; Angew. Chem. Int. Ed. 1998, 37, 894-908.

(5) van Leusen, D.; Hessen, B. Organometallics 2001, 20, 224-226.

(6) (a) Holovics, T. C.; Deplazes, S. F.; Toriyama, M.; Powell, D. R.; Lushington, G. H.; Barybin, M. V. Organometallics 2004, 23, $2927-$ 2938. (b) Barybin, M. V.; Holovics, T. C.; Deplazes, S. F.; Lushington G. H.; Powell, D. R.; Toriyama, M. J. Am. Chem. Soc. 2002, 124, $13668-$ 13669. (c) Knox, G. R.; Pauson, P. L.; Wilson, D.; Solčániová, E.; Toma, S. Organometallics 1990, 9, 301-306. (d) El-Shihi, T.; Siglmüller, F. Herrmann, R.; Carvalho, M. F. N. N.; Pombeiro, A. J. L. J. Organomet. Chem. 1987, 335, 239-247.

(7) See, for example: Elschenbroich, C. Organometallchemie, 4th ed.; Teubner: Stuttgart, Germany, 2003; Chapter 15.4.3.1.

(8) (a) Mingos, D. M. P. J. Chem. Soc., Dalton Trans. 1996, 561-566. (b) Pathaneni, S. S.; Desiraju, G. R. J. Chem. Soc., Dalton Trans. 1993, 319322.

(9) See, for example: (a) White-Morris, R. L.; Stender, M.; Tinti, D. S.; Balch, A. L.; Rios, D.; Attar, S. Inorg. Chem. 2003, 42, 3237-3244. (b) WiltonEly, J. D. E. T.; Ehrlich, H.; Schier, A.; Schmidbaur, H. Helv. Chim Acta 2001, 84, 3216-3232. (c) Irwin, M. J.; Manojlović-Muir, L.; Muir K. W.; Puddephatt, R. J.; Yufit, D. S. J. Chem. Soc. Chem. Commun. 1997, 219-220. (d) Schneider, W.; Angermaier, K.; Sladek, A.; Schmidbaur, H. Z. Naturforsch. B 1995, 51, 790-800.

(10) Reviews: (a) Pyykkö, P. Angew. Chem. 2004, 116, 4512-4577; Angew. Chem., Int. Ed. 2004, 43, 4412-4456. (b) Gimeno, M. C.; Laguna, A Gold Bull. 2003, 36, 83-92. (c) Fackler, J. P., Jr. Inorg. Chem. 2002, 41 6959-6972. (d) Schmidbaur, H. Gold Bull. 2000, 33, 3-10. (e) Pyykkö, P. Chem. Rev. 1997, 97, 597-636. (f) Schmidbaur, H. Chem. Soc. Rev. 1995, 23, 391-400.

(11) See, for example: (a) Liau, R.-Y.; Mathieson, T.; Schier, A.; Berger, R. J. F.; Runeberg, N.; Schmidbaur, H. Z. Naturforsch. B. 2002, 57, 881889. (b) Bachman, R. E.; Fioritto, M. S.; Fetics, S. K.; Cocker, T. M. J. Am. Chem. Soc. 2001, 123, 5376-5377. (c) Mathieson, T.; Schier, A.; Schmidbaur, H. J. Chem. Soc., Dalton Trans. 2001, 1196-2000. (d) Bachman, R. E.; Bodolosky-Bettis, S. A.; Glennon, S. C.; Sirchio, S. A. J. Am. Chem. Soc. 2000, 122, 7146-7147. (e) Jia, G.; Payne, N. C.; Vittal, J. J.; Puddephatt, R. J. Organometallics 1993, 12, 4771-4778. (f) Jia G.; Puddephatt, R. J.; Vittal, J. J.; Payne, N. C. Organometallics 1993, 12, 263-265. (g) Eggleston, D. S.; Chodosh, D. F.; Webb, R. L.; Davis L. L. Acta Crystallogr., Sect. C 1986, 42, 36-38. (h) Esperas, S. Acta Chem. Scand., Ser. A 1976, 30, 527-530.

(12) (a) Che, C.-M.; Yip, H.-K.; Wong, W.-T.; Lai, T.-F. Inorg. Chim. Acta 1992, 197, 177-182. (b) Che, C.-M.; Wong, W.-T.; Lai, T.-F.; Kwong, H.-L. J. Chem. Soc., Chem. Commun. 1989, 243-244.

(13) See, for example: (a) Mendizabal, F.; Pyykkö, P.; Runeberg, N. Chem Phys. Lett. 2003, 370, 733-740. (b) Codina, A.; Fernández, E. J.; Jones, P. J.; Laguna, A.; López-de-Luzuriaga, J. M.; Monge, M.; Olmos, M. E.; Pérez, J.; Rodríguez, M. A. J. Am. Chem. Soc. 2002, 124, 6781-6786. (c) Hunks, W. J.; Jennings, M. C.; Puddephatt, R. J. Inorg. Chem. 2002 41, 4590-4598.

(14) Braga, D.; Maini, L.; Paganelli, F.; Tagliavini, E.; Casolari, S.; Grepioni, F. J. Organomet. Chem. 2001, 637-639, 609-615.

(15) (a) Manners, I. Synthetic Metal-Containing Polymers; Wiley-VCH Weinheim, Germany, 2004. (b) Wöhrle, D.; Pomogailo, A. D. Metal Complexes and Metals in Macromolecules; Wiley-VCH: Weinheim, Germany, 2003. (c) Archer, R. D. Inorganic and Organometallic Polymers; Wiley-VCH: New York, 2001. (d) Kingsborough, R. P.; Swager, T. M. Prog. Inorg. Chem. 1999, 48, 123-231.

(16) Reviews: (a) Puddephatt, R. J. Macromol. Symp. 2003, 196, 137-144. (b) Puddephatt, R. J. Coord. Chem. Rev. 2001, 216-217, 313-332.

(17) (a) Boyd, R. W. Nonlinear Optics; Academic Press: London, 1992. (b) Shen, Y. R. Ann. Phys. Chem. 1980, 40, 327-351.

(18) Ohtsuka, T.; Sato, Y.; Uosaki, K. Langmuir 1994, 10, 3658-3662.

(19) (a) Young, J. T.; Boerio, F. J.; Zhang, Z.; Beck, T. L. Langmuir 1996, 12, 1219-1226. (b) Debe, M. K. J. Appl. Phys. 1984, 55, 3354-3366. JA0436244 